УДК 32.019.51

МЕДУШЕВСКИЙ Николай Андреевич - доктор политических наук, доцент кафедры культуры мира и демократии ЮНЕСКО; факультет истории, политологии и права Российского государственного гуманитарного университета (125993, Россия, г. Москва, Миусская пл., 6; Lucky5659@yandex.ru)

\title{
ПОЛИТИКА ПАМЯТИ В ЕВРОПЕЙСКОМ СОЮЗЕ КАК ИНСТРУМЕНТ РЕАЛИЗАЦИИ ИНТЕГРАЦИОННОГО ПРОЦЕССА
}

\begin{abstract}
Аннотация. Концепция политики памяти сегодня является одним из ключевых элементов современного европейского политического дискурса. Политика памяти во многом может рассматриваться как продолжение более комплексной политики мягкой силы и даже как элемент гибридной войны. Основной функцией политики памяти выступает интеграция европейского общества с целью создания единого общеевропейского представления о прошлом. Предполагается, что реализация политики по привлечению внимания европейцев к конкретным историческим событиям повлияет на их картину мира и будет способствовать росту их европейской самоидентификации, уровень который на данный момент крайне низок.

Особенно сильно на европейской политике памяти отразилось включение в состав ЕС государств Восточной Европы, которые заявили о необходимости изменения официальной политики памяти в пользу включения в нее событий послевоенной истории стран, находившихся к востоку от «железного занавеса». Изучение технологий формирования политики памяти и ее содержания становится как никогда актуальным.
\end{abstract}

Ключевые слова: политика памяти, идентичность, интеграция, европейские ценности, холокост, сталинизм, нацизм, синтетическая история

E вропейский союз представляет собой крупнейший в мире интеграционный проект, который объединяет на едином политико-экономическом пространстве более полумиллиарда человек. При этом каждый гражданин ЕС обладает собственным восприятием культуры, традиций, религии и исторического прошлого. Как показывает статистика, несмотря на наличие европейского гражданства, лишь несколько процентов европейцев считают, что у них превалирует европейская идентичность, и только около половины рассматривают европейскую идентичность в качестве второй после национальной ${ }^{1}$.

В таких условиях актуализируется необходимость формирования универсального европейского менталитета и преодоления исторически обусловленных ментальных барьеров, препятствующих диалогу между государствами, нациями и рядовыми европейцами.

Первые шаги к достижению данной высокой цели были предприняты еще в начале 1950 гг, после того как 9 мая 1950 г. основатели ЕС сделали предложение о его создании. Примерно в этот же временно́й период начинает постепенно формироваться и европейская политика памяти, которая на тот момент была связана с единством переживаний, вызванных Второй мировой войной. Впоследствии происходило накопление и дробление информационных поводов, которые дополняли видение исторической памяти, однако фактически до конца XX в. она оставалась неконцептуализированной.

После того, как в начале 1990-х гг. процесс интеграции перешел в активную фазу, возник спрос и на формирование общности исторической памяти европейцев через политику.

\footnotetext{
${ }^{1}$ European citizenship. Report. - Standard Eurobarometer. № 83. Spring 2015. URL: http://ec.europa.eu/ commfrontoffice/publicopinion/archives/eb/eb83/eb83_citizen_en.pdf (accessed 14.10.2018).
} 
Политику памяти можно определить как моделирование коллективной памяти политическими агентами с использованием политических технологий, которые позволяют акцентировать внимание общественности на одних исторических событиях и замалчивать другие, формируя у реципиентов стереотипизированное мышление. Во многом политика памяти сопряжена с феноменом выборочной, или избирательной памяти индивида [Collins, Loftus 1975], который получает массовое выражение в контексте навязчивой популяризации через СМИ, систему образования и другие институты.

В частности, в аспекте формирования исторической памяти в ЕС особое место уделяется образовательной политике, т.к. предполагается, что именно через правильную расстановку акцентов в учебном процессе можно добиться создания у молодых европейцев новой исторической базы знаний. Кроме того, дополнительный эффект может быть обеспечен через различные стрессовые события, в числе которых наиболее значимым является война, формирующая одностороннее и очень устойчивое восприятие событийного ряда.

Политика памяти нацелена на формирование, в определенном смысле, синтетической истории, в которой внимание акцентируется только на «нужных» моментах, для того чтобы сформировать у реципиентов новое мировоззрение, в рамках которого они предстанут как единая общность. Как следствие, политика памяти становится востребованным и популярным инструментом практически во всех обществах, стремящихся к консолидации, но ее использование во многих случаях противопоставляет общество, в котором она реализуется, обществам других государств, где доминирует альтернативное представление об истории.

Здесь следует отметить, что Европейский союз не является исключением из данной практики, т.к. тоже стремится к консолидации через моделирование исторического прошлого. Однако пример ЕС достаточно специфичен, т.к. Евросоюз включает большое число государств, исторически относившихся к разным регионам, на которых реализовывались противоречивые практики исторического генезиса.

Объединяясь постепенно, Европейский союз фактически оказался вынужденным постоянно трансформировать свое «официальное представление» об исторической памяти, которая изначально была связана со странами - основательницами ЕС, затем была расширена на Германию, Испанию, Португалию и Грецию, характеризовавшиеся авторитарным и тоталитарным историческим прошлым. Последующий этап расширения и вовсе оказался связанным с присоединением бывших социалистических республик, характеризовавшихся явным отрицанием своего исторического прошлого и желанием приравнять коммунистический режим к нацизму, т.е. фактически кардинально трансформировать уже сложившееся у старых стран Европы представление об исторической памяти в пользу ее расширения.

Разбор феномена европейской исторической памяти разные авторы начинают с различных исторических моментов, связанных с эволюцией интеграционного процесса ЕС. В рамках данной работы нас в первую очередь интересует современный этап, отсчет которого можно условно начать с 2012-2013 гг. Причина установки такой отправной точки связана с тем, что к этому моменту Европейский союз уже сформировался в его текущем варианте, и была пройдена последняя волна интеграции, однако дезинтеграционные тенденции, в числе которых Брексит, реакция Польши и Венгрии на миграционный кризис, констатация принципа «Европа двух скоростей» и др., еще не получили своего развития.

Также характерно, что в 2013 г. вопрос реализации направленной политики памяти начинает широко обсуждаться европейскими парламентариями. 
Именно в 2013 г. Комитет Европейского парламента по культуре и образованию создает запрос на создание аналитической записки по теме: «вропейская историческая память: политика, проблемы и перспективы» [Prutsch 2013], которая готовится по итогам реализации программы «Европа для граждан» 2006-2013 гг., впервые в ЕС ориентированной на принципы формирования политики памяти, но перед запуском программы «Европа для граждан» 20142020 гг., которая содержит уже четкую программу формирования исторической памяти в ЕC [Council regulation... 2014].

Хотя обозначенная аналитическая записка не является официальным документом, она, тем не менее, отражает ключевые идеи, характеризовавшие европейскую политику памяти в данный исторический период, и является свидетельством дискурса этого периода.

Авторы записки напрямую указывают, что политика памяти не обязательно должна отражать «исторические реалии» и включает в себя определенную степень субъективности, основанной на оценочных суждениях. В данной связи, очевидно, существуют риски фальсификации истории в угоду конъюнктурным интересам. С их точки зрения, единственным возможным ограничителем подобной фальсификации могут служить свобода слова и активная деятельность гражданского общества, и то лишь при условии неангажированности последнего. В качестве показательного примера здесь можно упомянуть статус холокоста в официальной европейской исторической картине, любые попытки переоценки которого вызывают резкую критику, чреваты уголовным преследованием [Капинус, Додонов 2007] и не могут служить предметом обсуждения в образовательной среде или структурах гражданского общества ${ }^{1}$. Тем не менее в Европейском союзе периодически возникают ситуации, бросающие вызов даже этому фундаментальному правилу ${ }^{2}$, что свидетельствует, на наш взгляд, о неустойчивости общеевропейской исторической политики памяти.

Тем не менее тенденция к созданию общеевропейской политики памяти в ЕС неизбежна, т.к. без формирования единого представления о прошлом невозможно стремиться к общему будущему. В данной связи европейские аналитики констатируют необходимость комбинации трех уровней истории, а именно индивидуального, национального и наднационального, в целях их интеграции, отмечая при этом, что данные уровни с большой долей вероятности окажутся противоречивыми и потребуют корректировки.

Корректировка и универсализация исторической памяти не могут и не должны быть оторванными от реально существующих представлений людей, т.е. речь не идет о формировании «ложных воспоминаний». Европейские аналитики скорее предлагают работать с исходными данными с опорой на национальную историческую память, которая не является представлением о национальной истории в принципе, а представляет собой набор знаковых событий, ориентация на которые упрощает общее восприятие исторического процесса в определенном регионе и фактически создает конкретный продукт, который может продаваться, рекламироваться, популяризироваться и при этом соотноситься с другими аналогичными продуктами, произведенными в других регионах Европейского союза [Anderson 1983: 187-207].

Это требование находит свое отражение в действующей сегодня программе

${ }^{1}$ European Parliament resolution on remembrance of the Holocaust, anti-Semitism and racism. 27.01.2005. - Official Journal of the European Union. C 253 E. 13.10.2005. P. 37-39. URL: http://eur-lex.europa.eu/ LexUriServ/LexUriServ.do?uri=OJ:C:2005:253E:0037:0039: EN:PDF (accessed 07.05.2019).

2 Wyciekły rządowe instrukcje. Co ministrowie mają mówić o Holokauście? - Wprost. 12.01.2018. Доступ: https://www.wprost.pl/polityka/10103825/wyciekly-rzadowe-instrukcje-co-ministrowie-maja-mowic-oholokauscie.html (проверено 07.05.2019). 
«Европа для граждан» 2014-2020 гг. [Council regulation... 2014], в которой присутствует четкий список событий (см. табл. 1).

Таблица 1

Перечень исторических событий, обозначенных в программе «Европа для граждан» 2014-2020 гг. в качестве приоритетных

\begin{tabular}{|c|c|}
\hline \multirow{2}{*}{2016} & 1936 Начало гражданской войны в Испании \\
\hline & 1956 Политическая и социальная мобилизация в Центральной Европе \\
\hline \multirow{4}{*}{2017} & 1991 Начало югославских войн \\
\hline & $\begin{array}{l}1951 \text { Принятие Конвенции Организации Объединенных Наций о статусе } \\
\text { беженцев в связи с ситуацией с беженцами после Второй мировой войны в } \\
\text { Европе }\end{array}$ \\
\hline & $\begin{array}{l}1917 \text { Социально-политические революции, падение империй и их влияние на } \\
\text { политический и исторический ландшафт Европы }\end{array}$ \\
\hline & $\begin{array}{l}1957 \text { Римский договор и начало европейской экономической } \\
\text { интеграции }\end{array}$ \\
\hline \multirow{4}{*}{2018} & $\begin{array}{l}1918 \text { Окончание Первой мировой войны - рост национальных государств } \\
\text { и неспособность создать европейское сотрудничество и достичь мирного } \\
\text { сосуществования }\end{array}$ \\
\hline & 1938/1939 Начало Второй мировой войны \\
\hline & 1948 Начало «холодной войны» \\
\hline & 1948 Гаагский конгресс и интеграция Европы \\
\hline \multirow{4}{*}{2019} & $\begin{array}{l}1968 \text { Протест и движения за гражданские права, вторжение в Чехословакию, } \\
\text { студенческие протесты и антисемитская кампания в Польше }\end{array}$ \\
\hline & Выборы в Европейский парламент 1979 г. \\
\hline & $\begin{array}{l}1989 \text { Демократические революции в Центральной и Восточной Европе и } \\
\text { падение Берлинской стены }\end{array}$ \\
\hline & 2004 - 15 лет расширения ЕС в Центральной и Восточной Европе \\
\hline \multirow{3}{*}{2020} & 1950 Декларация Роберта Шумана \\
\hline & 1990 Германское воссоединение \\
\hline & 2000 Провозглашение Хартии основных прав ЕС \\
\hline
\end{tabular}

Все события из перечня могут быть четко разделены на две группы - позитивные и негативные, причем обе группы распределены по временно́му периоду равномерно, что призвано обеспечить системное воздействие на целевую аудиторию. Характеризуя позитивные события, следует отметить, что все они связаны с процессом европейской интеграции, которая позиционируется как высшее благо, создававшееся десятилетиями и испытывавшее негативное воздействие со стороны множества исторических кризисов.

Характеризуя комплекс негативных исторических событий, следует отметить его избирательность. При ближайшем рассмотрении становится очевидным, что во многих случаях источники негативных событий коренятся за пределами территории современного Евросоюза.

Наряду с популяризацией истории манипулирование исторической памятью создает эффект мифологизации исторических событий, значение которого 
находит выражение в сплочении общества и росте доверия (веры) к определенным связанным с мифом ценностям. Так, национальная интерпретация прошлого имеет тенденцию отрицать исторически подтвержденные, но негативные факты и выставлять на первый план события с позитивным значением, имевшие «национальное» значение и обозначавшие конкретных победителей и побежденных.

Эффект мифологизации четко просматривается в данных программах, особенно когда речь идет о негативных исторических практиках. «Тоталитаризм XX века лишил граждан их основных прав, исключив их из общественной жизни: евреи под нацистским режимом; политические “девианты” под коммунистическими режимами» [Council regulation... 2014]. Характерно, что в данной программе, ни в описании, ни в числе исторических дат, ничего не говорится о режимах Франко, Муссолини, Салазара или режиме «черных полковников» в Греции, т.к., вероятно, обращение к событиям, связанным с данными режимами, могло бы негативно повлиять на интеграционный процесс через «неприятные» и «спорные» воспоминания.

Особняком в данном перечне стоит Германия. Современная политика памяти Европейского союза фактически основана на порицании нацизма во всех его проявлениях, а нацизм, в свою очередь, напрямую связывается с гитлеровской Германией и событиями Второй мировой войны. Тем не менее Германия в данной системе ценностей уже на протяжении долгого времени не рассматривается как ответственная сторона, а представляется как страна, освобожденная от нацизма и победившая его в себе [Herf 1997]. Это можно трактовать как своего рода исторический миф, значение которого, тем не менее, не абсолютно, т.к., к примеру, в последние годы польские политики активно спекулируют на теме ответственности и невыплаченных репараций.

Число ключевых событий формируемой в ЕС исторической памяти не статично и в разных источниках отличается. В их числе неизменно называются Вторая мировая война ${ }^{1}$ и достижения европейской интеграции ${ }^{2}$. С конца XX в. перечень был также дополнен памятью о холокосте и «памятью тоталитаризма XX века», под которым понимается, прежде всего, социализм и сталинизм [Prutsch 2013].

Некоторые аналитики рассматривают более широкий список событий и упоминают «европейское наследие», к которому относят Возрождение и Просвещение, а также отмечают роль Первой мировой войны и делают акцент на источниках легитимации ЕС, включая основные акты, флаг, гимн и памятную дату - День Европы.

Рассмотренные нами программы не просто содержат перечень событий, но и ориентируют на четкие цели [Council regulation... 2014: 3]. В частности, в Регламенте Совета (ЕС) № 390/2014 от 14 апреля 2014 г., устанавливающем второй этап программы «Европа для граждан», было констатировано, что целями программы являются:

- внесение вклада в понимание гражданами ЕС его истории и многообразия;

\footnotetext{
${ }^{1}$ European Parliament resolution on the $60^{\text {th }}$ anniversary of the end of the Second World War in Europe on 8 May 1945. 12.05.2005. - Official Journal of the European Union. 20.04.2006. P. 392-394. URL: http://eur-lex. europa.eu/LexUriServ/LexUriServ.do?uri=OJ:C:2006:092E:0392:0394:EN:PDF (accessed 07.05.2019).

2 Report on the proposal for a Council regulation establishing for the period 2014-2020 the programme «Europe for Citizens». Brussels. 11.12.2012. P. 5-46. URL: http://www.europarl.europa.eu/sides/getDoc. do?pubRef=-//EP//NONSGML+REPORT+ A7-2012-0424+0+DOC+PDF+V0//EN (accessed 07.05.2019); Decision No 1194/2011/EU of the European Parliament and of the Council of 16 November 2011 establishing a European Union action for the European Heritage Label, 16 February 2011. - Official Journal of the European Union. L 303. 22.11.2011. P. 1-9. URL: http://eur-lex.europa.eu/LexUriServ/LexUriServ.do?uri $=$ OJ:L:2011:303:0001:0009:EN:PDF (accessed 07.05.2019).
} 
- усиление европейского гражданства и улучшение условий для гражданского и демократического участия на уровне $\mathrm{EC}$;

- повышение осведомленности о воспоминаниях, общей истории и ценностях;

- содействие демократическому участию граждан на уровне ЕС.

Характеризуя цели программы, следует отметить, что они, во-первых, апеллируют к конкретным историческим событиям и, во-вторых, предполагают интерпретацию данных событий в русле четкого набора либеральных ценностей, в числе которых отрицание антисемитизма, антигипсизма (ненависть к цыганам), ксенофобии, гомофобии и других форм нетерпимости, а также защита свободы слова, свободы собраний и иных прав человека.

Характеризуя общие тенденции развития общеевропейской политики памяти, можно констатировать, что официально проводимая политика памяти в исследуемый период стала более четкой и однозначной. Исторические события получают позитивную либо негативную трактовку, которая начинает популяризироваться через систему образования, СМИ и институты гражданского общества. Здесь показательна одна из целей программы «Европа для граждан» 2014-2020 гг., посвященная «активному европейскому воспоминанию». Речь идет о финансировании музеев и мест памяти, в т.ч. бывших концентрационных лагерей, а также объектов и архивов, связанных с массовыми депортациями и массовым истреблением. Этот исторический фокус основан на предположении, что для того, чтобы полностью оценить значение основополагающих европейских (союзных) принципов, таких как свобода, демократия и уважение прав человека, жизненно важно, чтобы были очевидными примеры нарушения этих принципов в XX в., что, в свою очередь, требует включения подобной информации в систему образования стран - членов ЕС.

В свою очередь, анонсированная потребность в популяризации такого типа знания вызывает у экспертов вопрос о необходимом уровне финансирования. Характерно, что в период начала реализации первой программы «Европа для граждан» на развитие исторической памяти европейцев отводилось всего $4 \%$ общего финансирования, или 215 млн евро. Начиная с 2010 г. объем финансирования стал постепенно увеличиваться ${ }^{1}$, и, кроме того, было улучшено согласование блоков программы. В частности, вопрос формирования исторической памяти получил дополнительное раскрытие в таких рубриках, как «Активные граждане для Европы», «Активное гражданское общество в Европе» и «Вместе для Европы». Второй этап программы 2014-2020 гг. предусматривал уже большее финансирование - в размере $18 \%$ от исходной суммы в 229 млн евро плюс дополнительные дотации [Prutsch 2013].

Несмотря на активную реализацию политики исторической памяти в ЕС в последние годы, реализуемый подход во многом чреват созданием черно-белой картины мира [Prutsch 2013]. С позиции критиков официального подхода политика памяти Европейского союза не может ограничиваться штампами об «уни-

1 Decision No 1904/2006/EC of the European Parliament and of the Council of 12 December 2006 establishing for the period 2007 to 2013 the programme «Europe for Citizens» to promote active European citizenship. 12 December 2006. - Official Journal of the European Union. L 378. 27.12.2006. P. 32-40. URL: http://eur-lex.europa.eu/LexUriServ/LexUriServ.do?uri=CELEX:32006D1904:EN:NOT (accessed 07.05.2019); Decision No 1358/2008/EC of the European Parliament and of the Council of 16 December 2008 amending Decision No 1904/2006/EC establishing for the period 2007 to 2013 the programme «Europe for Citizens» to promote active European citizenship. 16 December 2008. - Official Journal of the European Union. L 350. 30.12.2008. P. 58. URL: http://eur-lex.europa.eu/LexUriServ/LexUriServ.do?uri=OJ:L:2008:350:0058 :0059:EN:PDF (accessed 07.05.2019). 
кальности холокоста» ${ }^{1}$ и «безусловном зле нацизма и сталинизма» ${ }^{2}$, а также неоспоримом благе интеграционного процесса в Европе, т.к. это примитивизирует многогранную реальность.

Также данная модель не учитывает, к примеру, феномен колониализма, что препятствует восприятию реальных практик интеграции ЕС. Соответственно, с позиции скептиков формируемая в ЕС историческая память должна быть основана на критическом восприятии европейскими обществами в первую очередь своей национальной истории.

Достигнуть подобного критического уровня, по мнению экспертов, можно, руководствуясь универсальными гуманистическими ценностями и участвуя в открытой дискуссии, которая обеспечит взаимопонимание и примирение. Участие в дискуссии, в свою очередь, потребует отказа от понятия «историческая правда» и его нормативного закрепления, что, в конечном итоге, приведет к интеграции истории и новому мышлению.

Тем не менее на данный момент подобная комплексная политика памяти в Европейском союзе не сложилась, и, более того, в контексте миграционного и финансового кризисов последних лет обострились многие исторические противоречия и были реанимированы воспоминания об исторической несправедливости, которые препятствуют примирению. В немалой степени этому способствовали недавние политические события, которые многие аналитики связывают с пересмотром системы миропорядка в целом. Ключевыми событиями здесь следует считать украинский кризис и активизацию деятельности стран Вышеградской группы в вопросах отстаивания своих прав на европейской политической арене.

Все это заставляет скептически взглянуть на рассмотренные выше практики формирования единой исторической памяти и констатировать, что, как таковой, единой исторической памяти в ЕС нет, и, более того, в ближайшей перспективе она не сможет сформироваться, т.к. европейские политики ориентируются исключительно на «мягкие практики» насаждения «правильных» взглядов, которые фактически перестают работать в условиях кризиса (экономического, финансового, миграционного) и в контексте роста правого популизма и национализма, нацеленных на дезинтеграцию.

В данной связи можно согласиться с эстонской исследовательницей М. Мальксоо, которая еще в 2009 г. констатировала, что в Европе нет общей исторической памяти и существует не менее четырех вариантов политики памяти, в т.ч. атлантическо-западноевропейская, немецкая, восточно- и центральноевропейская, российская, которые находятся в состоянии борьбы и нацелены на подавление друг друга [Mälksoo 2009].

М. Мальксоо представила политические усилия Польши и Прибалтики в период после вступления в ЕС как попытку плюрализировать способы быть европейскими государствами в исторической ретроспективе, однако сегодняшняя политическая практика показывает, что обозначенный процесс плюрализации создал основу для современного сепаратизма внутри ЕС со сто-

\footnotetext{
${ }^{1}$ European Parliament declaration on the remembrance of the Holocaust. 7 July 2000. - Official Journal of the European Communities. 24.04.2001. P. 503. URL: http://eur-lex.europa.eu/LexUriServ/LexUriServ.do?uri $=\mathrm{OJ}: \mathrm{C}: 2001: 121: 0503: 0504: \mathrm{EN}: \mathrm{PDF}$ (accessed 14.10.2018).

2 Declaration of the European Parliament on the proclamation of 23 August as European Day of Remembrance for Victims of Stalinism and Nazism. 23 September 2008. - Official Journal of the European Union. 14.01.2010. P. 57-59. URL: http://eur-lex.europa.eu/LexUriServ/LexUriServ.do?uri=OJ:C:2010:008E :0057:0059:EN:PDF (accessed 07.05.2019).
} 
роны отдельных восточноевропейских государств. Таким образом, историческая память материализуется уже в новой политической риторике 1.

\section{Список литературы}

Капинус О.С., Додонов В.Н. 2007. Ответственность за разжигание расовой, национальной и религиозной вражды, а также за другие «преступления ненависти» по уголовному праву зарубежных стран. - Законы России: опыт, анализ, практика. № 8. С. 76-85.

Anderson B. 1983. Imagined Communities: Reflections on the Origin and Spread of Nationalism. London: Verso. 240 p.

Collins A.M., Loftus E.F. 1975. A Spreading-activation Theory of Semantic Processing. - Psychological Review. Vol. 82. No. 6. P. 407-428.

Council regulation (EU) No 390/2014 of 14 April 2014 establishing the «Europe for Citizens» programme for the period 2014-2020. 17.04.2014. P. 3. URL: https://eacea. ec.europa.eu/europe-for-citizens_en (accessed 07.05.2019).

Herf J. 1997. Divided Memory: The Nazi Past in the Two Germanys. Cambridge, Mass.: Harvard University Press. 527 p.

Mälksoo M. 2009. The Memory Politics of Becoming European: The East European Subalterns and the Collective Memory of Europe. - European Journal of International Relations. Vol. 15. No. 4. P. 653-680.

Prutsch M.J. 2013. European Historical Memory: Policies, Challenges and Perspectives. Note. URL: http://www.europarl.europa.eu/RegData/etudes/note/ join/2013/513977/IPOL-CULT_NT(2013)513977_EN.pdf (проверено 07.05.2019).

\section{MEMORY POLICY IN THE EUROPEAN UNION AS A TOOL FOR THE IMPLEMENTATION OF THE INTEGRATION PROCESS}

Abstract. The concept of the policy of memory today is one of the key elements of modern European political discourse. In many ways, one can consider it as a continuation of a more comprehensive policy of soft power, and even as an element of a hybrid war. The main function of the policy of memory is the integration of the European society with the aim of creating a single pan-European view of the past. The author assumes that the implementation of the policy of attracting the attention of Europeans to specific historical events will affect their picture of world and will contribute to the growth of their European identity, the level of which is currently extremely low.

The inclusion of Eastern European states into the European Union, which proclaim the necessity of changing the official memory policy in favor of including the events of the post-war history of the countries located to the east of the Iron Curtain, influenced particularly strong the European memory policy. The study of technologies of the policy of memory and its content becomes more relevant than ever.

Keywords: memory policy, identity, integration, European values, Holocaust, Stalinism, Nazism, synthetic history

1 Туск пригрозил выходом Польши из Евросоюза. - РИА Новости. 07.11.2018. Доступ: https://ria.ru/ world/20181107/1532245556.html (проверено 07.05.2019). 